
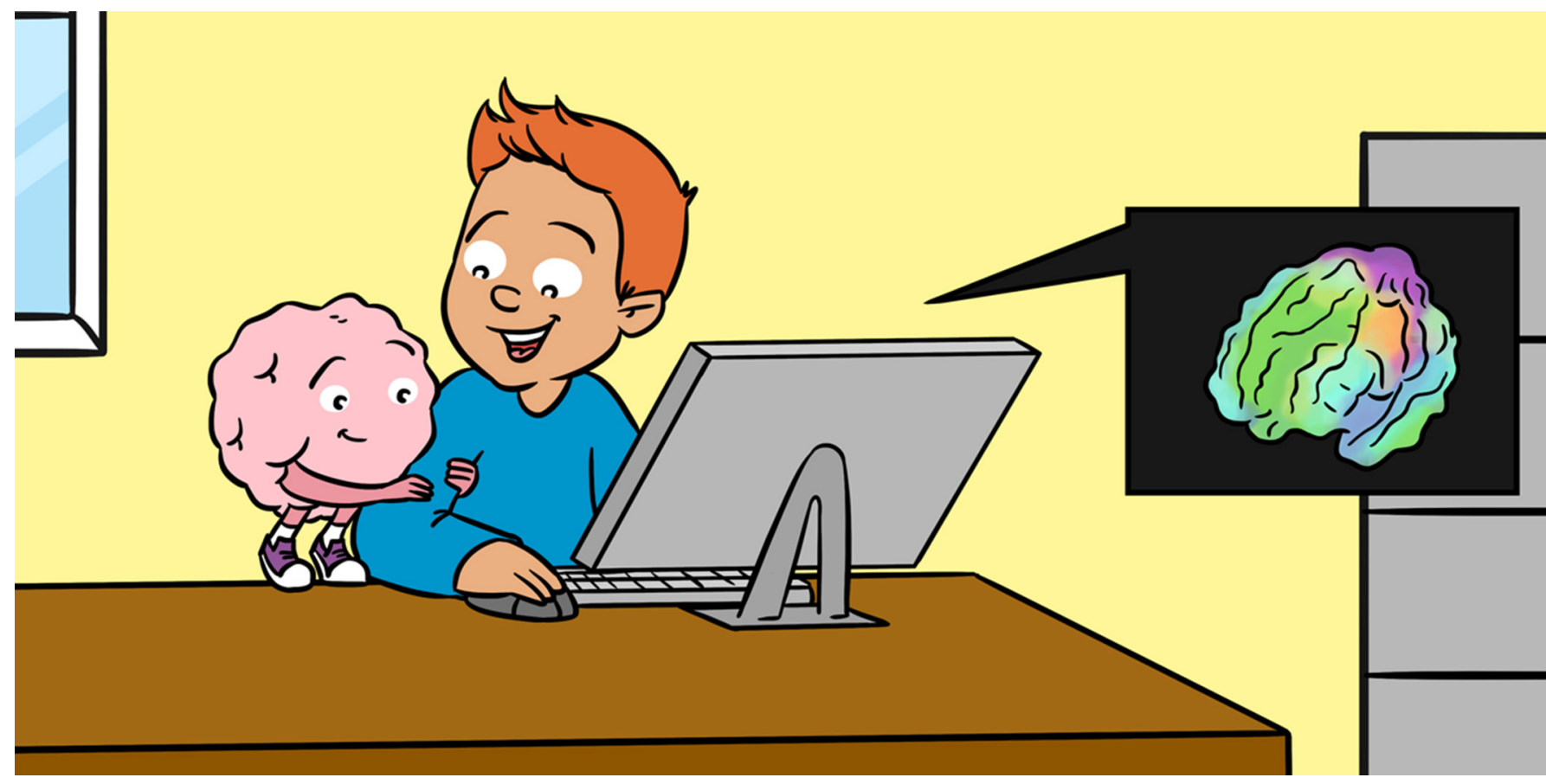

\title{
INTERACTIVE 3D BRAIN HELPS YOU LEARN HOW THE BRAIN IS ORGANIZED
}

\author{
Paul S. Scotti ${ }^{1 *}$, Arman P. Kulkarni ${ }^{2}$, Matan Mazor ${ }^{3}$, Eduard Klapwijk ${ }^{4}$ and Alexander Huth ${ }^{5,6}$ \\ ${ }^{1}$ Department of Psychology, The Ohio State University, Columbus, $\mathrm{OH}$, United States \\ ${ }^{2}$ Department of Biomedical Engineering, University of Wisconsin-Madison, Madison, WI, United States \\ ${ }^{3}$ Wellcome Centre for Human Neuroimaging, University College London, London, United Kingdom \\ ${ }^{4}$ Erasmus School of Social and Behavioral Sciences, Erasmus University Rotterdam, Rotterdam, Netherlands \\ ${ }^{5}$ Department of Neuroscience, The University of Texas at Austin, Austin, TX, United States \\ ${ }^{6}$ Department of Computer Science, The University of Texas at Austin, Austin, TX, United States
}

\section{YOUNG REVIEWERS:}

\begin{tabular}{|l|l} 
AGE: 13 & CLAUDIO \\
AGE: 11 \\
AGIOT: 12
\end{tabular}

Which parts of your brain help you to talk to and understand others? How about recognizing your friends by their faces? Or remembering the last time you ate your favorite dessert? In this article we describe EduCortex, a free educational tool that allows you to play with a 3D brain, to discover how different parts of the brain work together to help you do things. By clicking on the brain, you will see words that are most associated with the selected brain region. For example, by entering a word like "language," you can see the parts of the brain related to language. EduCortex works by using an online collection of information that automatically checks over 14,000 scientific papers, to see how the content of each paper relates to different brain parts. 
Figure 1

Modified screenshot of EduCortex. The left half of the brain is shown, while the right half is mostly hidden from view. Labels and cartoon eyes show the brain's orientation. The colors of the brain correspond to the colored words in our word cloud (Figure 2) such that brain areas colored red are those that perform functions related to motor skills (physical movement), and areas colored green perform functions related to memory.

1 You can use EduCortex by going to www.paulscotti.com/ educortex

\section{CEREBRAL CORTEX}

The outermost layer of the brain.

2 We used a software library called PyCortex [2] to visualize and interact with the brain.

3 This process is done automatically by the online database Neurosynth [3].

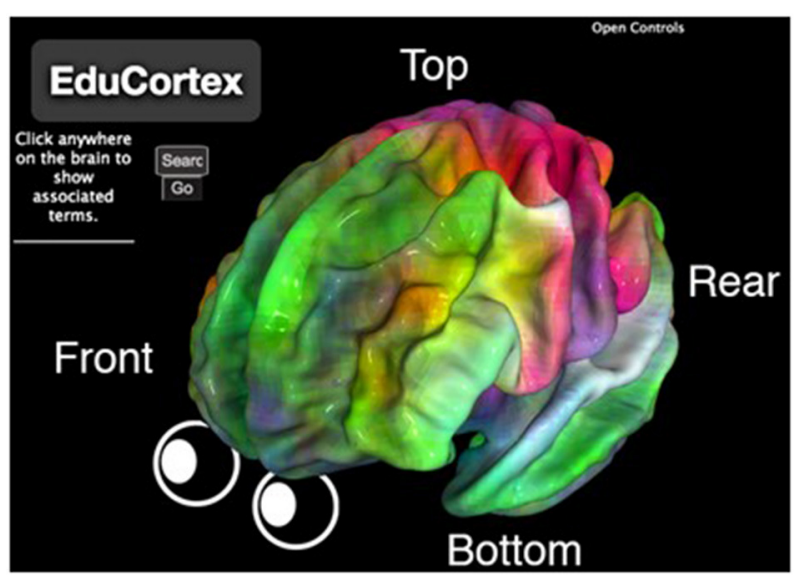

Figure 1

\section{WHAT IS EDUCORTEX?}

EduCortex is an educational tool that helps people to learn about the brain. EduCortex allows you to play with a 3D brain, to learn which parts of the brain perform which functions [1] $]^{1}$. When you first visit the EduCortex website, you will be greeted with a colorful human brain (Figure 1). The real human brain is a grayish organ with a reddish tone due to blood flow, but the brain that you see in EduCortex is unrealistically colorful, to help you learn. The EduCortex brain shows the cerebral cortex, which is the outside surface of the brain. This is the part of the head you would see if the skin and skull were removed. Note that the brain in this tool is an average of many adult brains, but individual brains come in different shapes and sizes.

You can click and drag the brain to rotate it, and you can use the scroll wheel on your mouse (or right click and drag) to make the brain smaller or larger. Other camera tools can be found by clicking "Open Controls" at the top right ${ }^{2}$. At the bottom right of the screen, there is a word cloud. The colors of the words match the colors that you see on the brain. For example, motor skill (functions related to physical movement) is colored red on the word cloud, and the region of the brain involved with physical movement is also colored red. The words in the word cloud represent those terms that best explain the brain activity in each area, and this information is compiled from thousands of scientific papers ${ }^{3}$.

If you click anywhere on the brain, a list of underlined words will be displayed on the left side of the screen. These are the terms that are most associated with the brain region that you clicked (within 6 millimeters). Try clicking one of these terms and the brain will change color. Red parts of the brain are regions that are associated with the term that you clicked, with a darker red indicating a stronger association - these are regions most involved in the function described by the word that you clicked. You might notice that most search 
terms do not map to just one single part of the brain. This is because, for most tasks, the brain works in networks of regions that talk to each other.

There is also a search box on the left side of the screen. Try typing in a word like "language," "face," or "memory." You can also enter anatomical words, if you know them, such as "occipital"-the brain lobe that processes information from the eyes. When you click "Go," the brain will again change color, and brain regions that are highly linked to the search word will appear in red.

\section{BRAIN MAPS}

Brain maps are one component of EduCortex. A brain map is similar to a world map. A world map shows information about different continents and countries, and a brain map shows information about different parts of the brain. When you enter "language" into EduCortex, it shows a brain map on which redder regions are more involved with language processing. EduCortex's brain maps were constructed from 14,371 scientific papers about the brain!

How were all these scientific papers turned into a single brain map for every term? First, each paper was labeled with a set of terms that appeared frequently in the paper. Second, for each term, the brain locations that were reported in each paper were noted. Third, for each brain location, the probability of each term appearing across all papers is calculated. Finally, a brain map for every term was created in which higher probabilities were represented as redder brain locations. EduCortex takes all these brain maps and displays them in a 3D, interactive web browser.

\section{WORD CLOUD}

The word cloud is another important component of EduCortex. We created a group of terms that best explained the brain activities described in all the scientific papers. What do we mean by this? Imagine that you had to choose only three food items that can be mixed together to make your meals. What would be on your list? For example, you can put bread, tomatoes, and cheese on the list, to make a pizza. But bread, tomatoes, and cheese will not let you make cereal,

PRINCIPAL COMPONENTS ANALYSIS

A method of simplifying data into a small group of the most important parts. ice cream, or fruit salad. Instead, you might want each of your three food items to be more basic ingredients, like flour, eggs, and milk. When combined in different quantities, more basic ingredients can create many more dishes. This more or less describes the technique we used, called principal component analysis [4], except we used brain-related terms instead of meals. 
Figure 2

The colors of the brain in Figure 1 relate to the colors of the words in EduCortex's word cloud. For example, the red parts of the brain are related to physical movement ("motor"). The word cloud was created using a technique called principal component analysis, in which terms that made the largest impact on the three simplified brain maps are shown.

\section{FUNCTIONAL} SPECIALIZATION

The idea that different areas of the brain are involved in different functions.

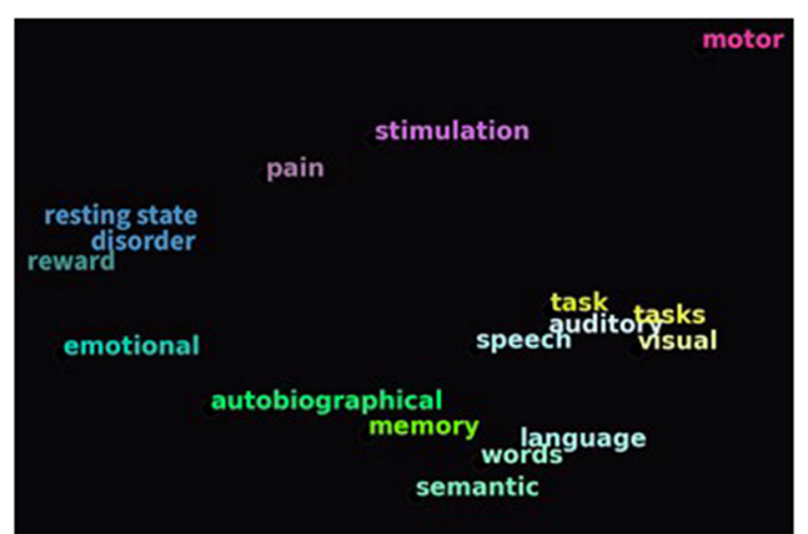

Figure 2

We started with 950 brain-related terms from the scientific papers and created maps of the brain locations associated with these terms. We then used principal component analysis to simplify the 950 brain maps into only three brain maps that, when combined in various ways, could reasonably create the original 950 brain maps. We then asked which of the 950 brain maps had the largest impact on these three simplified brain maps. It is these terms that are depicted in the word cloud (Figure 2).

\section{THE BRAIN SHOWS FUNCTIONAL SPECIALIZATION}

One important educational use for EduCortex is to help you understand how different parts of the brain are involved in different functions. For centuries, many researchers and physicians have been studying and labeling structures in animal and human brains by dissecting brains from dead bodies. Luckily, thanks to modern brain imaging techniques, we can now study the brain in living humans. Researchers have people perform certain tasks in a brain scanner to see which parts of the brain become active. Putting together evidence from many studies can tell us which parts of the brain are specialized for performing certain functions. This is called functional specialization, and it is one thing that is easy to see using EduCortex.

Functional specialization refers to how different parts of the brain carry out different roles. For instance, the back of the brain is heavily involved in processing visual information, allowing you to see and to understand what you see, while the top of the brain is heavily involved with physical sensation and movement, like feeling the heat of the sun on your back as you walk to school. The brain can also be specialized for very specific behaviors. For example, a region of cortex called the fusiform face area seems to be specialized for processing human faces [5]. Try entering "face" into EduCortex to see where this area is located. 
Despite this functional specialization, the human brain cannot be described as thousands of functionally separate regions. Different areas of the brain are always talking with each other, creating a large-scale network [6]. As you explore EduCortex, it will become apparent that a single region of the brain is usually never alone in performing a function. Further, brain regions are excellent multitaskers, often being involved in many different functions!

\section{CONCLUSION}

The brain is the most complex organ in the human body, and because of this complexity, it can be difficult to learn about the brain's structure and how it works. We hope that EduCortex can help! If you wonder, "What part of the brain processes faces?," then you can use EduCortex to search for "face," and see that activation happens mostly in the fusiform face area [5], with smaller amounts of activation in other areas of the brain. You can also perform the opposite process by clicking on a brain region to see the terms associated with that area. This allows you to freely explore the layout of the brain, to understand functional specialization. If you want to learn more about the scientific names of the structures of the brain, EduCortex can help with that, too! We think that EduCortex will be helpful for both children and adults who are looking to better understand what the brain looks like and how it functions. We hope that you enjoy using EduCortex to learn about the brain!

\section{REFERENCES}

1. Scotti, P. S., Kulkarni, A., Mazor, M., Klapwijk, E., Yarkoni, T., and Huth, A. G. 2020. EduCortex: browser-based 3D brain visualization of fMRI meta-analysis maps. J. Open Source Educ. 3:75. doi: 10.21105/jose.00075

2. Gao, J. S., Huth, A. G., Lescroart, M. D., and Gallant, J. L. 2015. Pycortex: an interactive surface visualizer for fMRI. Front. Neuroinform. 9:23. doi: 10.3389/fninf.2015.00023

3. Yarkoni, T., Poldrack, R. A., Nichols, T. E., Van Essen, D. C., and Wager, T. D. 2011. Large-scale automated synthesis of human functional neuroimaging data. Nat. Methods 8:665. doi: 10.1038/nmeth.1635

4. Pearson, K. 1901. On lines and planes of closest fit to systems of points in space. Philos. Mag. 2:559-72. doi: 10.1080/14786440109462720

5. Kanwisher, N., McDermott, J., and Chun, M. M. 1997. The fusiform face area: a module in human extrastriate cortex specialized for face perception. J. Neurosci. 17:4302-11. doi: 10.1523/JNEUROSCI.17-11-04302.1997

6. Bellec, P., Perlbarg, V., Jbabdi, S., Pélégrini-Issac, M., Anton, J. L., Doyon, J., et al. 2006. Identification of large-scale networks in the brain using fMRI. Neuroimage 29:1231-43. doi: 10.1016/j.neuroimage.2005.08.044

SUBMITTED: 22 June 2020; ACCEPTED: 22 July 2021; PUBLISHED ONLINE: 24 August 2021. 
EDITED BY: Caroline A. Niziolek, University of Wisconsin-Madison, United States

CITATION: Scotti PS, Kulkarni AP, Mazor M, Klapwijk E and Huth A (2021) Interactive 3D Brain Helps You Learn How the Brain Is Organized. Front. Young Minds 9:575131. doi: 10.3389/frym.2021.575131

CONFLICT OF INTEREST: The authors declare that the research was conducted in the absence of any commercial or financial relationships that could be construed as a potential conflict of interest.

COPYRIGHT @ 2021 Scotti, Kulkarni, Mazor, Klapwijk and Huth. This is an open-access article distributed under the terms of the Creative Commons Attribution License (CC BY). The use, distribution or reproduction in other forums is permitted, provided the original author(s) and the copyright owner(s) are credited and that the original publication in this journal is cited, in accordance with accepted academic practice. No use, distribution or reproduction is permitted which does not comply with these terms.

\section{YOUNG REVIEWERS}

\section{CLAUDIO, AGE: 13}

I love to play basketball and skateboard, I love science and I love to read.
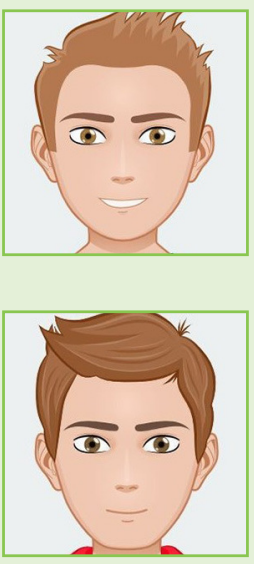

\section{ELLIOT, AGE: 11}

Elliot is 11 . He enjoys learning about science and is interested in sport too! He loves playing football, running and supporting Manchester United. He also likes gaming and chatting to his friends. He enjoys traveling and hopes to learn more about science when he goes to secondary school.

\section{TOBY, AGE: 12}

Toby is 12. He is interested in science but mainly loves football and swimming. He plays football twice a week and swims six times a week! He also likes watching football and is a big fan of Manchester United. He enjoys traveling and finding out about new things.

\section{AUTHORS}

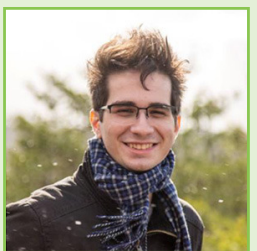

\section{PAUL S. SCOTTI}

Paul Scotti comes from New York City and is currently a Ph.D. student in cognitive psychology at The Ohio State University. He loves to play board games and to look at pretty pictures of brains. He wishes that all scientific papers were written in a way that appealed to young kids. *scottibrain agmail.com 

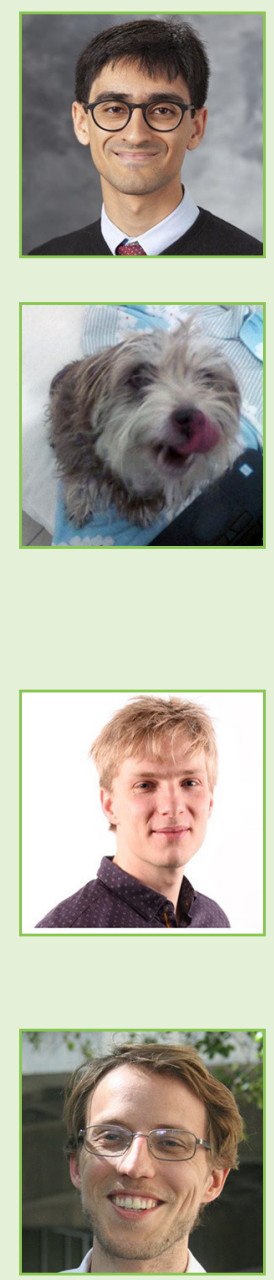

Arman Kulkarni is from Irvine, California and is currently a Ph.D. student in biomedical engineering at the University of Wisconsin, Madison. He enjoys games, art, and most things related to mystery. He believes that teaching should be based on simple explanations and engaging visual aids and animations. apkulkarni2@wisc.edu

\section{MATAN MAZOR}

Matan Mazor is a Ph.D. student at the Institute of Neurology, University College London. He is passionate about philosophy of science and mind, and interested in the ethical aspects of doing science, such as the ethics of animal experimentations for the study of the mind or the importance of data sharing for scientific progress. He also enjoys drawing and eating dairy-free ice-cream (chocolate $>$ pistachio $>$ hazelnut).

\section{EDUARD KLAPWIJK}

Eduard Klapwijk lives and works in Leiden, the Netherlands. He is a psychologist and studies brain development in children and adolescents. He has two young kids who will hopefully enjoy reading Frontiers for Young Minds when they are older. Besides doing research and spending time with his family, Eduard loves to ride his bike, cook, and read books.

\section{ALEXANDER HUTH}

I am an assistant professor of neuroscience and computer science at the University of Texas at Austin. My research uses computational methods to model how the brain processes language and represents meaning. 